\title{
In-vitro evaluation of the influence of repeat pours of addition silicone impressions on the dimensional accuracy of resultant casts: An original research study
}

\begin{abstract}
Background and Aim: For miscellaneous purposes, the prosthodontists and dental laboratory technicians usually attempt repeated pouring of the impression in order to avoid expenses and curb upon the chair-side time. There are numerous factors which can affect dimensions of subsequent casts on repeated pouring. These include the process of polymerization, temperature and the material used to fabricate the replica of working cast. The sole aim of this study was to evaluate if repeated pouring of addition silicone impression would influence the dimensional accuracy of resultant casts. Materials \& Methods: Addition silicone impression material along with tray adhesive were used to evaluate the influence of repeat pours on the dimensional accuracy of resultant casts at various time intervals $i . e$. at 15 minutes, 75 minutes, 24 hours and 7 days. Vision measurement machine was used for measurement of dimensions. A metal control model of $8^{*} 6^{*} 2 \mathrm{~cm}$ was made with abutments. Various dimensional markings and measurements (for inter-abutment distance \& intra-abutment distance) were completed. All 80 resultant casts were along with the master model was dimensionally evaluated with "Vision Measurement Machine". Statistical Analysis and Results: Statistical analysis was completed by SPSS (statistical package for social sciences) version 21.0 and Epi-info version 3.0. The result of this study showed that working dies obtained from Addition silicone at various time intervals i.e. 15 minutes, 75 minutes, 24 hours and 7 days exhibited insignificant dimension changes clinically. The $p$-value was taken significant when less than $0.05(p<0.05)$ and Confidence interval of $95 \%$ was taken. Post-Hoc Bonferroni test showed no significant difference for the inter-interval comparison of mean inter-abutment distance (Line 2-3). Conclusion: Within the limitations of the study authors concluded that the addition silicone impression material could be preferred material in the field of prosthodontics for repeated pouring up-to 7 days due to its favorable qualities like dimensional accuracy and stability, elastic recovery from undercuts, low creep and moderate to high tear resistance.
\end{abstract}

Key words: Addition Silicon, Impression, Accuracy, Vision Measurement Machine

\section{Introduction :}

In dentistry, accurate and dimensionally stable impressions are the first step towards fabrication of a successful prosthesis. An impression is a record, a facsimile of the oral tissues taken at an unstrained rest position or in various positions of displacement.[1] As we all are aware that the final impression must be precise to construct restoration with ultimate marginal fit, interproximal and occlusal contacts.[2] Whenever we are attempting impression, dimensional accurateness is crucial for the quality of fixed prosthodontic therapy. On the other hand, impression technique is a significant factor affecting the accuracy.[3] Polyvinyl silicones (PVS) impression materials are also known as addition silicones. Vinyl polysiloxane has the second highest tear energy, next to polysulfide. However, materials such as polysulfide, with extremely high tear

\begin{tabular}{|l|c|}
\hline \multicolumn{3}{|c|}{ Access this article online } \\
\hline $\begin{array}{l}\text { Website: } \\
\text { www.ujds.in }\end{array}$ & Quick Response Code \\
\hline $\begin{array}{l}\text { DOI: } \\
\text { https://doi.org/10.21276/10.21276/ujds.2020.6.2.17 }\end{array}$ & \\
\hline
\end{tabular}

energies may suffer permanent deformation instead of tearing. If an impression material is significantly distorted when removed from an undercut, it is not possible to detect this defect in the impression until the finished crown is seated in the patient's mouth. However, torn margins can often be discovered immediately after the impression is removed from the mouth. Thus, materials with high tear energies must also have adequate elastic recovery properties.[4] The

${ }^{1}$ PRITAM A ${ }^{2}$ MALL $\mathbf{N}$

${ }^{1}$ Prosthodontist and Implantologist, Aashray Nursing Home, Tilkamanjhi, Bhagalpur, Bihar

${ }^{2}$ Department of Prosthodontics, Shree Bankey Bihari Dental College and Research Centre, Ghaziabad, India

Address for Correspondence : Dr. Amrita Pritam Aashray Nursing Home, Tilkamanjhi, Bhagalpur, Bihar Email: dhirk160@gmail.com

Received : 18 July 2020, Published : August 2020

How to cite this article: Pritam, A., \& Mall, N. (2020). An In-Vitro Evaluation of the influence of repeat pours of addition silicone impressions on the dimensional accuracy of resultant casts: an original research study. UNIVERSITY JOURNAL OF DENTAL SCIENCES, 6(2): 33-8. 
accurateness and practical efficiencies of prosthesis solely depends on an precise impression which is regenerated on a gypsum model. The ultimate accurateness of the impression with repeat pours is very crucial because duplicate casts are frequently necessitated for different laboratory procedures like wax the particular retainers, making the connectors of fixed partial denture and attempting the wax pattern etc. Such duplicate casts are employed as working or refractory casts with the intention that the master cast remains unchanged. Since, the final dimensions of successive casts on repeat pouring could be distressed by polymerization. Polymerization engrosses cross linking of the polymer chains resulting in the decrease of spatial volume. Not only the polymerization but temperature as well changes the sizes both during and after the clinical set. The material employed to make the duplicate or working cast can also be changed in dimensions like gypsum expansion.[5] Most of the times dentist wants to have two or more casts out of the same impressions, to avoid the problems associated with repeated impression making. Obtaining multiple accurate casts from the single dental impression is advantageous in generating duplicate dies, assembling multiple individual cast restorations on an intact cast, replicating the abutmentgingiva relationship, and enhancing the edentulous ridge anatomical architecture.[6] There are several things that can alter the dimensions of subsequent casts on repeated pouring. These comprised of process of polymerization, temperature and the material to construct the duplicate of working cast.[7] In this modern era, a lot of importance is put on the technique and type of the impression material. The dilemma forced by the lab technician as well as the prosthodontist clearly suggests that repeated pouring of the impression is done in order to avoid expenses and curb upon the chair-side time. Whatever the reason be, the purpose of the present study was to confirm whether repeated pouring is a boon or a bane. Hence the aim of this study was to evaluate if repeated pouring of addition silicone impression would influence the dimensional accuracy of resultant casts.

\section{Materials \& Methods:}

This study was planned, outlined, abstracted and conducted in the Department of Prosthodontics, Shree Bankey Bihari Dental College and Research Centre, Ghaziabad, U.P. The study has been approved by ethical committee. Addition silicone impression material (soft putty/regular set: Aquasil/Dentsply) along with tray adhesive (Coltene) were used to evaluate the influence of repeat pours on the dimensional accuracy of resultant casts at various time intervals i.e at 15 minutes, 75 minutes, 24 hours and 7 days.
Rim lock impression trays were used to make the impressions. Die fabrication was done by using Type IV gypsum material (Kalabhai Karson Pvt. Ltd, Ultrarock) mixed using vacuum mixer. Vision measurement machine was used for measurement of dimensions. The investigation was initiated by making measurements on casts obtained from impressions of a metal control model which represent a dental arch of approximately $8 * 6 * 2 \mathrm{~cm}(\mathrm{~L} * \mathrm{~B} * \mathrm{H})$ with four parallel sided abutments. All four abutments were labeled as 1,2, $3 \& 4$, at the position of canines and 1st molars of right and left sides. The height and diameter of all the 4 abutments were kept identical at the time of manufacturing (Figure 1). The dimensional values (intra-abutment distance) for height (line O), bucco-lingual diameter (line $\mathrm{M}$ ) and mesio-distal diameter (line B) were $3.8709 \mathrm{~mm}, 7.9125 \mathrm{~mm}$ and 7.9988 $\mathrm{mm}$ respectively. The abutments were prepared with reference cross grooves on occlusal and proximal surfaces for reference measurements. The abutment dimensions and the lines marked on it are explained in Figure $2 \& 3$. The dimensional markings (for inter-abutment distance) (Figure 1) was line $2-3 \&$ line $1-4$, line $1-2 \&$ line $3-4$, line $1-3 \&$ line 2-4 for inter arch measurement, antero-posterior measurement and cross-arch measurement respectively. All distances were measured from centre of occlusal surface of all the dies. The direct measurements obtained from the model were used as control for comparison of measurements from cast poured from the impressions of model. With the help of NDYAG laser, reference lines of 40 microns were marked on the occlusal surface of the abutment. The tray with the addition silicone impression material was seated gently over the master model to attempt impression. The cast was retrieved and subsequent casts will be fabricated using the same impression. A total of four casts were fabricated (Figure 4). Each impression was poured repeatedly and sub grouped according to the different storage time intervals 15 minutes, 75 minutes, 24 hours, 7 days. Twenty such impressions were made and four casts obtained from each impression. Thus 80 resultant casts were obtained. Each measurement i.e. the master model and the cast was read with a "Vision Measurement Machine" (Figure 6). The measurement for the mesio-distal diameter (Line B), the measurement for the bucco-lingual diameter (Line $\mathrm{M}$ ), the measurement for the occluso gingival height (Line $\mathrm{O}$ ) was measured for all the four abutments. The inter-abutment distance was calculated from the centre of occlusal surface located on the left abutment till the centre of the occlusal surface located on the right working abutment. Antero-posterior distance was measured from the centre of the occlusal surface located on the left anterior and posterior abutment (Line 3-4) and on the right anterior and 
posterior abutment (Line 1-2). Cross-arch distance was measured from the centre of the occlusal surface located on the right posterior abutment to the left anterior abutment (Line 1-3) and right anterior abutment to the left posterior abutment (Line 2-4, Figure 5). All the data was tabulated and statistical test was performed using the statistical package for statistical analysis using statistical software Statistical Package for the Social Sciences version 21 (IBM Inc., Armonk, New York, USA)

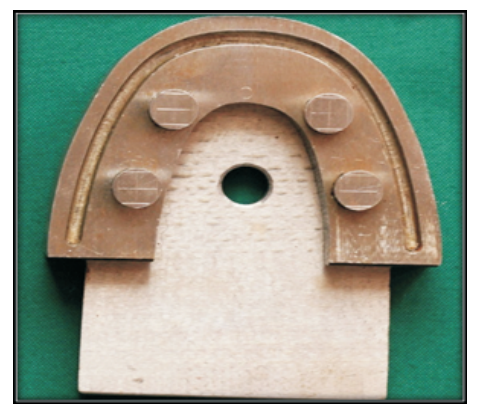

Figure 1: Master model showing four abutments 1,2,3,4

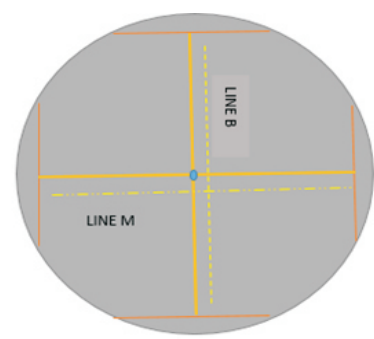

Figure 2: Schematic diagram showing mesio-distal (Line B) and bucco-lingual (Line $\mathrm{M}$ ) diameters of all four abutments in the master model

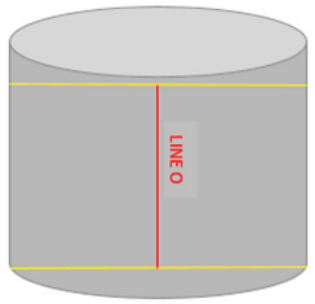

Figure 3: Schematic diagram showing occluso-gingival height $(\mathrm{O})$ of all four abutments in the master model

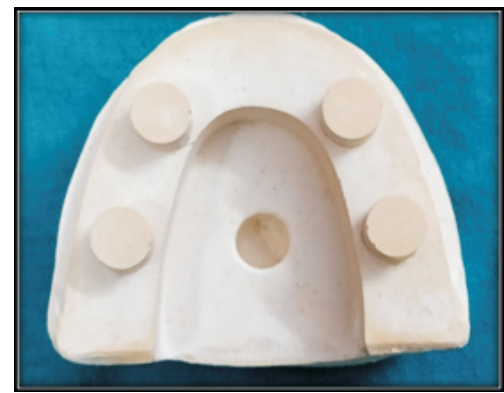

Figure 4: Master cast

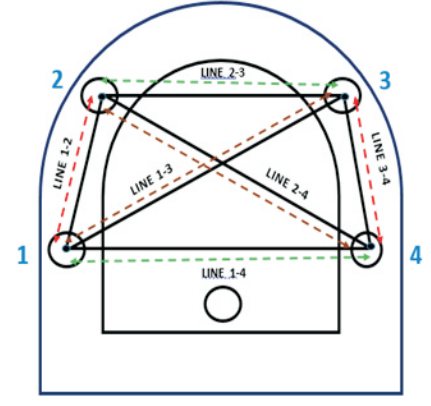

Figure 5: Schematic diagram of master model showing interabutment distance (line 1-4) and (line 2-3), antero-posterior distance (line 1-2) and (line 3-4), cross -arch distance (line 24) and line (line 1-3)

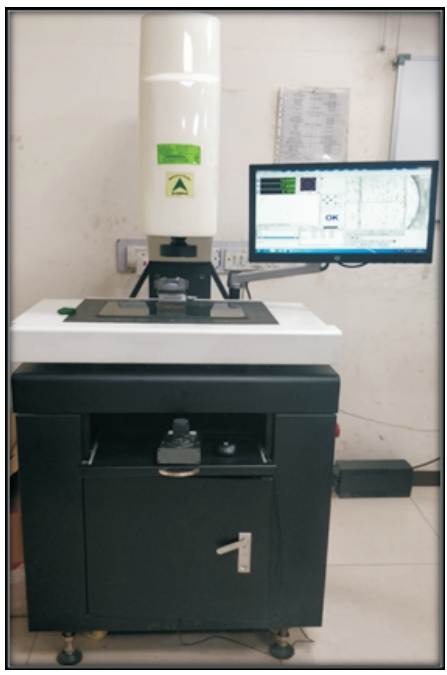

Figure 6: Vision measurement machine measuring the master model dimensions

\section{Statistical analysis and results:}

Descriptive statistics was performed by calculating mean, standard deviation, frequencies and percentages for the Continuous variables. Categorical variables were summarized as frequencies and percentages. SPSS (statistical package for social sciences) version 21.0 and Epi-info version 3.0 was used for attempting all tests and data analysis. The pvalue was taken significant when less than $0.05(\mathrm{p}<0.05)$ and Confidence interval of $95 \%$ was taken. The result of this study showed that working dies obtained from Addition silicone at various time intervals i.e. 15 minutes, 75 minutes, 24 hours and 7 days exhibited insignificant dimension changes clinically. Statistically, the inter-abutment distance (Line 1-4 and Line 2-3), the cross arch distance ( Line 1-3 and Line 2-4 ), the antero-posterior distance (Line 1-2 and Line 3-4) of the dies became continuously smaller when compared to the master model as the pouring time interval increased and the 
intra-abutment distance (Line $\mathrm{M}$, Line B, Line $\mathrm{O}$ ) increased when compared to the master model as the pouring time interval increased from 15 minutes to 7 days. Mean and standard deviation values of inter-abutment distance (Line 23) and (Line 1-4), (in mm) for each group at different time intervals has been described in Table $1 \& 2$. Mean and standard deviation values of antero-posterior distance (line 12) (in $\mathrm{mm}$ ) for each group at different time intervals has been described in table 3 while the similar analysis for (Line 3-4) have been shown in Table 4. Furthermore, similar analysis for cross-arch measurement (Line 2-4) \& (Line 1-3) have been illustrated in Table $5 \& 6$ respectively. ANOVA analysis for mean inter-abutment distance (Line 2-3) showed very imperative inferences which has been shown in Table 7. The mean Inter-abutment distance (Line 2-3) was compared between at 15 minutes, at 75 minutes, at 24 hours and at 7 days using the Repeated-measures ANOVA test. There was no significant difference in mean Inter-abutment distance (Line 2-3) between at 15 minutes, at 75 minutes, at 1 day and at 7 days. Evaluation of mean inter-abutment distance (Line 2-3) Using Post-Hoc Bonferroni test was done and tabulated in Table 8. It showed no significant difference for the interinterval comparison of mean Inter-abutment distance (Line 2-3).

Table 1: Mean and standard deviation values of interabutment distance (Line 2-3) (in $\mathrm{mm}$ ) for each group at different time intervals

\begin{tabular}{|c|c|c|c|c|c|c|}
\hline $\begin{array}{c}\text { Inter-abutment } \\
\text { distance (Line 2- } \\
\text { 3) }\end{array}$ & Mean & $\begin{array}{c}\text { Std. } \\
\text { Deviation }\end{array}$ & $\begin{array}{c}\text { Std. } \\
\text { Error }\end{array}$ & Minimum & Maximum & Range \\
\hline At 15 minutes & 31.7314 & 0.0152 & 0.0034 & 31.7109 & 31.7514 & 0.0405 \\
\hline At 75 minutes & 31.7197 & 0.0129 & 0.0029 & 31.7002 & 31.7403 & 0.0401 \\
\hline At 24 hours & 31.6983 & 0.0087 & 0.0019 & 31.6803 & 31.7158 & 0.0355 \\
\hline At 7 days & 31.6538 & 0.0075 & 0.0017 & 31.6399 & 31.6721 & 0.0322 \\
\hline
\end{tabular}

Table 2: Mean and standard deviation values of interabutment distance (Line 1-4) (in $\mathrm{mm}$ ) for each group at different time intervals

\begin{tabular}{|c|c|c|c|c|c|c|}
\hline $\begin{array}{c}\text { Inter-abutment } \\
\text { distance (Line 1- } \\
\text { 4) }\end{array}$ & Mean & $\begin{array}{c}\text { Std. } \\
\text { Deviation }\end{array}$ & $\begin{array}{c}\text { Std. } \\
\text { Error }\end{array}$ & Minimum & Maximum & Range \\
\hline At 15 minutes & 45.3673 & 0.0061 & 0.0014 & 45.3598 & 45.3873 & 0.0275 \\
\hline At 75 minutes & 45.3422 & 0.0058 & 0.0013 & 45.3321 & 45.3508 & 0.0187 \\
\hline At 24 hours & 45.3235 & 0.0056 & 0.0013 & 45.3111 & 45.3316 & 0.0205 \\
\hline At 7 days & 45.2847 & 0.0033 & 0.0007 & 45.2785 & 45.2901 & 0.0116 \\
\hline
\end{tabular}

Table 3: Mean and standard deviation values of anteroposterior distance (Line 1-2) (in $\mathrm{mm}$ ) for each group at different time intervals

\begin{tabular}{|c|c|c|c|c|c|c|}
\hline $\begin{array}{c}\text { Antero- } \\
\text { posterior } \\
\text { distance (Line } \\
\text { 1-2) }\end{array}$ & Mean & $\begin{array}{c}\text { Std. } \\
\text { Deviation }\end{array}$ & $\begin{array}{c}\text { Std. } \\
\text { Error }\end{array}$ & Minimum & Maximum & Range \\
\hline At 15 minutes & 21.1898 & 0.0098 & 0.0022 & 21.1748 & 21.2093 & 0.0345 \\
\hline At 75 minutes & 21.1650 & 0.0055 & 0.0012 & 21.1549 & 21.1781 & 0.0232 \\
\hline At 24 hours & 21.1472 & 0.0029 & 0.0006 & 21.1399 & 21.1511 & 0.0112 \\
\hline At 7 days & 21.1056 & 0.0051 & 0.0011 & 21.0999 & 21.1182 & 0.0183 \\
\hline
\end{tabular}

Table 4: Mean and standard deviation values of antero- posterior distance (Line 3-4) (in $\mathrm{mm}$ ) for each group at different time intervals

\begin{tabular}{|c|c|c|c|c|c|c|}
\hline $\begin{array}{c}\text { Antero-posterior } \\
\text { distance (Line 3- } \\
\text { 4) }\end{array}$ & Mean & $\begin{array}{c}\text { Std. } \\
\text { Deviation }\end{array}$ & $\begin{array}{c}\text { Std. } \\
\text { Error }\end{array}$ & Minimum & Maximum & Range \\
\hline At 15 minutes & 20.3917 & 0.0062 & 0.0014 & 20.3769 & 20.3995 & 0.0226 \\
\hline At 75 minutes & 20.3741 & 0.0030 & 0.0007 & 20.3699 & 20.3799 & 0.0100 \\
\hline At 1 day & 20.3657 & 0.0050 & 0.0011 & 20.3499 & 20.3735 & 0.0236 \\
\hline At 7 days & 20.3159 & 0.0067 & 0.0015 & 20.3011 & 20.3281 & 0.0270 \\
\hline
\end{tabular}

Table 5: Mean and standard deviation values of cross-arch measurement (Line 2-4) (in mm) for each group at different time intervals

\begin{tabular}{|c|c|c|c|c|c|c|}
\hline $\begin{array}{c}\text { Cross-arch } \\
\text { measurement } \\
\text { (Line 2-4) }\end{array}$ & Mean & $\begin{array}{c}\text { Std. } \\
\text { Deviation }\end{array}$ & $\begin{array}{c}\text { Std. } \\
\text { Error }\end{array}$ & Minimum & Maximum & Range \\
\hline At 15 minutes & 43.0654 & 0.0058 & 0.0013 & 43.0587 & 43.0793 & 0.0206 \\
\hline At 75 minutes & 43.0433 & 0.0036 & 0.0008 & 43.0363 & 43.0511 & 0.0148 \\
\hline At 24 hours & 43.0342 & 0.0034 & 0.0008 & 43.0291 & 43.0401 & 0.0110 \\
\hline At 7 days & 42.9849 & 0.0069 & 0.0015 & 42.9711 & 43.0001 & 0.0290 \\
\hline
\end{tabular}

Table 6: Mean and standard deviation values of cross-arch measurement (Line 1-3) (in $\mathrm{mm}$ ) for each group at different time intervals

\begin{tabular}{|c|c|c|c|c|c|c|}
\hline $\begin{array}{c}\text { Cross-arch } \\
\text { measurement } \\
\text { (Line 1-3) }\end{array}$ & Mean & $\begin{array}{c}\text { Std. } \\
\text { Deviation }\end{array}$ & $\begin{array}{c}\text { Std. } \\
\text { Error }\end{array}$ & Minimum & Maximum & Range \\
\hline At 15 minutes & 43.0485 & 0.0027 & 0.0006 & 43.0428 & 43.0519 & 0.0091 \\
\hline At 75 minutes & 43.0289 & 0.0008 & 0.0002 & 43.0267 & 43.0299 & 0.0032 \\
\hline At 24 hours & 43.0169 & 0.0027 & 0.0006 & 43.0111 & 43.0201 & 0.0090 \\
\hline At 7 days & 42.9645 & 0.0070 & 0.0016 & 42.9511 & 42.9867 & 0.0356 \\
\hline
\end{tabular}

Table 7: Mean inter-abutment distance (Line 2-3) using ANOVA test

\begin{tabular}{|c|c|c|c|c|}
\hline $\begin{array}{c}\text { Inter-abutment distance } \\
\text { (Line 2-3) }\end{array}$ & Mean & Std. Deviation & F-value & p-value \\
\hline At 15 minutes & 31.7314 & 0.0152 & 0.981 & $0.246^{\#}$ \\
\hline At 75 minutes & 31.7197 & 0.0129 & & \\
At 24 hours & 31.6983 & 0.0087 & - & - \\
\hline At 7 days & 31.6538 & 0.0075 & & \\
\hline
\end{tabular}

\# Non-significant difference

Table 8: Mean inter-abutment distance (Line 2-3) using PostHoc Bonferroni test

\begin{tabular}{|c|c|c|c|}
\hline \multicolumn{2}{|c|}{ Time Interval } & Mean Difference & p-value \\
\hline At 15 minutes & At 75 minutes & 0.0117 & $0.297^{\#}$ \\
\hline At 15 minutes & At 24 hours & 0.0330 & $0.140^{\#}$ \\
\hline At 15 minutes & At 7 days & 0.0780 & $0.088^{\#}$ \\
\hline At 75 minutes & At 24 hours & 0.0210 & $0.109^{\#}$ \\
\hline At 75 minutes & At 7 days & 0.0660 & $0.100^{\#}$ \\
\hline At 24 hours & At 7 days & 0.0440 & $0.090^{\#}$ \\
\hline \multicolumn{4}{|c}{ \# Non-significant difference }
\end{tabular}

\section{Discussion :}

Literature has well evidenced that a precise impression is the ultimate key to success of any treatment. An impression must replicate hard and soft tissues, prepared and adjacent teeth. These are required to ensure utmost biologically, mechanically, functionally and esthetically acceptable prosthesis. Dimensional constancy of any impression materials has been extensively debated in the dental literature.[8] Addition silicone impression material i.e. polyvinyl siloxane is the material of choice for most of 
prosthodontic works. It is because of its good qualities like dimensional accuracy and stability, elastic recovery from undercuts, low creep and moderate to high tear resistance. Nevertheless repeated pours may alter the final dimensions of the impressions because of the ongoing polymerization of addition silicone impression material. deformation of the impression material can be seen while retrieval of stone models when several casts are poured in the same impression.[2] The master model employed in our study was comparable to the standard die used to assess dimensional stability by Heidari and associates.[9] Similar model was used for making the impression in the research made of stainless steel was used by Heidari and associate 9 and Aalaei and colleagues 10 and in addition, it was similar to the pattern used in a study by Schleier and co-workers.[11] This kind of model has more dimensional stability compared to plaster or wax models. In the present study the material of choice is Aquasil soft putty i.e. addition silicone. Although in several studies the dimensional stability of some impression materials has been evaluated and compared, the number of studies about PVS is scarce. Aalaei and colleagues 10 demonstrated that PVS impression materials remain dimensionally stable up to 7 days. It has been found that the casts made from silicon impression materials are in a clinical range. Our findings are in line with all previous reports and could be attributed to the good elastic recovery of the polyvinyl siloxanes; this confirms the results of the other studies. Eames and fellow researchers 12 and Tjan and colleagues 13 reported that polyethers were found to be statistically equivalent to addition silicones and exhibited the least change dimensionally. It is suggested that in conditions that prevent the instant pouring of the impressions, only the stable materials must be chosen.[19] However, studies done by Thongthammachat and associates 14 have reported that polyether must be poured only once and within 24 hours after impression making. Polyether impression material shows absorption of water or fluids and the concurrent oozing of the water soluble plasticizer. This is one of the drawbacks of this material. Therefore the stored impression should be put in a dirt free, dried up and cool atmosphere to preserve its accurateness. The results of the present study revealed that repeated pouring of impressions at different time intervals did not statistically significantly affect the dimensional accuracy of the casts produced from addition silicone impression material. The study also exhibited that there was slight decrease in inter-abutment distance whereas the intraabutment distances increased slightly as the time interval increased. The progressive increase or decrease in dimensions of stone casts as time interval increased was due to contraction of the impression material, but these changes were statistically insignificant. The result of the present study was in accordance with study results of studies conducted by various researchers. $[2,4,12,15,16,17,18,13,14]$ The relative decrease in inter-abutment distance observed in the present study might be explained on the basis of pattern of polymerization shrinkage of the addition silicone impression material. The increase in intra-abutment distance observed in the present study may be due to the fact that impression material contracted towards the walls of the impression tray coated with tray adhesive. Polymerization shrinkage happened towards the restrained surface (tray) and away from the unrestrained (tooth) surface. Furthermore, impressions must be poured up to 1 week without undergoing any noteworthy deformation. This was mention in a study by Mehta R and co-researchers.[2] Though the present study showed no statistically significant differences in the accuracy of casts obtained at different time intervals but there are various limitations of the study. As the study was carried out in-vitro, it did not take in to account the effect of various intraoral conditions such as the effect of oral fluids, soft tissues, different arch form and the effect of undercuts. Similar limitations were also encountered by Aalaei and colleagues.[10] In this regards, literature has also well evidenced wherein various pioneer workers had come across different opinions and concepts.[19,20,21,22]

\section{Conclusion:}

Within the limitations of this study, authors have drawn few very significant conclusions. They stated that the interabutment distance decreased as the pouring time interval increased from 15 minutes to 1 week however the intraabutment distances increased as the pouring time interval increased from 15 minutes to 1 week. Additionally, all of the deviations of the stone casts from the master model were within a clinically acceptable range (less than 90 um). The addition silicone impression materials were dimensionally stable for 1 week period, even though preferable pouring time could be considered as 15 minutes.

\section{References:}

1. De Van MM. Basic principles in impression making. J Prosthet Dent. 2005;93:503-08.

2. Mehta R, Wadhwa S, Duggal N, Kumar A, Goel M and Pande S Influence of repeat pours of addition silicone impressions on the dimensional accuracy of casts. J Interdiscipl Med Dent Sci. 2014;2(108):1-13.

3. Caputi S,Varvara G. Dimensional accuracy of resultant casts made by a monophase, one-step and two-step, and a novel two-step putty/lightbody impression technique: an in vitro study. J Prosthet Dent. 2008;99:274-81. 
4. Ohsawa M, Finger W. Working time of elastomeric impression materials. Dent Mater. 1986;2:179-82.

5. Wadhwani CPK, Johnson GH, Lepe X, Rajgrodski AJ. Accuracy of newly formulated fast setting elastomeric impression materials. J Prosthet Dent. 2005;93:530-9.

6. Dounis KS, Dounis G, Ditmiyer MM, Ziebert GJ. Accuracy of successive casts for full arch fixed prostheses. Int J Prosthodont. 2010;23:446-9

7. Michalakis KX, Asar NV, Kapsampeli V, Magkavali-Trikka P, Pissiotis AL, Hirayama H. Delayed linear dimensional changes of five high strength gypsum products used for the fabrication of definitive casts. J Prosthet Dent. 2012;108(3):189-95.

8. Craig RG. A review of properties of rubber impression materials. J Mich Dent Assoc. 1977;59:254-61.

9. Heidari B ,Vafaei F, Izadi A, Saleh A, Dehbani Z, Khazaei S. Effect of Contact Time Between Silicone Impression Materials and Stone on Dimensional Stability of Resultant Cast. Avicenna J Dent Res. 2013;5(1):20-5.

10. Aalaei Sh, Rezaei Adli A, Mansoorali MR, Gholami F. Dimensional Stability of Two Polyvinyl Siloxane Impression Materials in Different Time Intervals. J Dent Biomater. 2015;2(4):155-61.

11. Schleier PE, Gardner FM, Nelson SK, Pashley DH. The effect of storage time on the accuracy and dimensional stability of reversible hydrocolloid impression material. J Prosthet Dent. 2001;86(3):244-50.

12. Eames WB, Wallace SW, Suway NB, Roger LB. Accuracy and dimensional stability of elastomeric impression materials. J Prosthet Dent. 1979;42:159-62.

13. Tjan AH, Whang SB, Tjan AH, Sarkissian R. Clinically oriented evaluation of the accuracy of commonly used impression material. J Prosthet Dent. 1986;56:4-8.

14. Thongthammachat S, Moore BK, Barco MT, Hovijitra S, Brown DT, Andres CJ. Dimensional accuracy of dental casts: Influence of tray material, impression material, and time. J Prosthodont. 2002;11:98108.

15. Lacy AM, Fukui H, Bellman T, Jendersen MD. Time dependent accuracy of elastomer impression materials Part II: Polyether, Polysulphide and Polyvinyl siloxanes. J Prosthet Dent. 1981;45:32933.

16. Marcinak CF, Draughn RA. Linear dimensional change in addition silicone impression material. J Prosthet Dent. 1982;47:411-3.

17. Williams PT, Jackson DG, Bergman W. An evaluation of the time dependent dimensional stability of eleven elastomeric impression materials. J Prosthet Dent. 1984;52:120-5.

18. Johnson GH, Craig RG. Accuracy of four types of rubber impression materials compared with time of pour and a repeat pour of models. J Prosthet Dent. 1985;53:484-490.

19. Thielke S, Serrano JG, Lepe X. A method for true coordinate threedimensional measurement of casts using a measuring microscope. $\mathbf{J}$ Prosthet Dent. 1998;80:506-510.

20. Wee AG. Comparison of impression materials for direct multi-implant impressions. J Prosthet Dent. 2000;83(3):323-31.

21. Ciesco JN, Malone WF, Sandrik JL, Mazur B. Comparison of elastomeric impression materials used in fixed prosthodontics. J Prosthet Dent. 1981;45:89-94.

22. Reddy SM, Vijitha D, Karthikeyan S, et al. Evaluation of dimensional stability and accuracy of autoclavable polyvinyl siloxane impression material. J Ind Prosthodont Soc. 2013;13:546-50. 